\title{
Multiple paternity and sporophytic inbreeding depression in a dioicous moss species
}

\author{
P Szövényi, M Ricca and AJ Shaw \\ Department of Biology, Duke University, Durham, NC, USA
}

\begin{abstract}
Multiple paternity (polyandry) frequently occurs in flowering plants and animals and is assumed to have an important function in the evolution of reproductive traits. Polyandry in bryophytes may occur among multiple sporophytes of a female gametophyte; however, its occurrence and extent is unknown. In this study we investigate the occurrence and extent of multiple paternity, spatial genetic structure, and sporophytic inbreeding depression in natural populations of a dioicous bryophyte species, Sphagnum lescurii, using microsatellite markers. Multiple paternity is prevalent among sporophytes of a female gametophyte and male genotypes exhibit significant skew in paternity. Despite significant spatial genetic structure in the population, suggesting frequent inbreeding, the number of inbred and outbred sporophytes was balanced, resulting in
\end{abstract}

an average fixation coefficient and population level selfing rate of zero. In line with the prediction of sporophytic inbreeding depression sporophyte size was significantly correlated with the level of heterozygosity. Furthermore, female gametophytes preferentially supported sporophytes with higher heterozygosity. These results indicate that polyandry provides the opportunity for postfertilization selection in bryophytes having short fertilization distances and spatially structured populations facilitating inbreeding. Preferential maternal support of the more heterozygous sporophytes suggests active inbreeding avoidance that may have significant implications for mating system evolution in bryophytes.

Heredity (2009) 103, 394-403; doi:10.1038/hdy.2009.82; published online 22 July 2009

Keywords: bryophytes; inbreeding; mating systems; reproductive skew; reproductive compensation; selective embryo abortion

\section{Introduction}

Male and female fecundity are often differently limited and this is thought to have led to a sexual conflict in animals (Trivers, 1972). Female fecundity is expected to be limited by egg production whereas male fecundity is usually limited by the number of mating events (Bateman, 1948; Arnold, 1994). This has crystallized to the general idea that female animals might maximize their fitness by mating with one male over a reproductive cycle. Nevertheless, females of many animals appear to mate with more than one male; they are polyandrous (e.g. Bateman, 1948; Birkhead and Møller, 1998 for a review; Tregenza and Wedell, 2000; Portnoy et al., 2007; Frentiu and Chenoweth, 2008). As mating with multiple males incurs extra female costs (Cornell and Tregenza, 2007), it is assumed that polyandry should either provide direct or indirect advantages over mating with only one male. Indirect genetic advantages such as the avoidance of mating with incompatible males, opportunities for sperm competition, and cryptic female choice, may explain the prevalence of polyandry in animals (see Cornell and Tregenza, 2007 for a review).

Polyandry is prevalent in seed plants too in which female reproductive success appears to be resource limited whereas male reproductive success is mainly

Correspondence: Dr P Szövényi, Department of Biology, Duke University, 139 Biological Sciences Bldg., Box 90338, Durham, NC 27708, USA.

E-mail:pis@duke.edu

Received 6 February 2009; revised 12 May 2009; accepted 4 June 2009; published online 22 July 2009 limited by pollen transport (Snow and Lewis, 1993; Campbell, 1998; Bernasconi, 2003; Knight et al., 2005). However, the effect of polyandry on female and male fitness, gene flow, and the evolution of reproductive structures in flowering plants have started to receive attention only in the past few years (Bernasconi, 2003; Teixeira and Bernasconi, 2007; Teixeira et al., 2009). In flowering plants, polyandry may increase overall female fitness of an individual either through pre- or postpollination selection. Mating with multiple mates may increase the possibility of mating with compatible males; it also permits pollen competition and therefore selection for pollen quality. Polyandry also increases the genetic diversity of offspring (Ellstrand and Marshall, 1986; Armbruster and Rogers, 2004; Bernasconi et al., 2004; Teixeira et al., 2009). As the number of ovules fertilized usually exceeds the number of mature seeds produced, seeds with different paternity may go through a postpollination selection process as well (Stephenson, 1981; Wiens, 1984; Korbecka et al., 2002). Consequently, polyandry may have important implications for the evolution of traits affecting the reception and donation of pollen and the evolution of mating systems.

Polyandry is assumed to have similar evolutionary implications in nonvascular embryophytes but information concerning its occurrence and extent is scarce (Haig and Westoby, 1988; Haig and Wilczek, 2006). Moss gametophytes can be either bisexual (producing both archegonia with eggs and antheridia with sperm; monoicous species) or unisexual (producing either archegonia or antheridia but not both; dioicous species). 
Unisexual gametophytes either outcross or undergo intergametophytic selfing (mating among haploid sibs from the same sporophyte), which is equivalent to 'selfing' in seed plants. Bisexual gametophytes are also capable of intragametophytic selfing (merging of gametes produced by the same genetic individual) resulting in a fully homozygous sporophyte generation. Owing to this difference bisexual gametophytes are expected to rapidly purge recessive deleterious mutations through intragametophytic selfing, whereas more genetic load is assumed to accumulate in populations of unisexual gametophytes (Eppley et al., 2007). This difference in the amount of genetic load is proposed to have led to greater sporophytic inbreeding depression in species with unisexual compared with bisexual gametophytes (Taylor et al., 2007). If the severity of sporophytic inbreeding depression is the primary force driving mating system evolution in bryophytes, species with unisexual gametophytes should be predominantly outcrossers. In contrast, species with bisexual gametophytes should predominantly inbreed because of the negligible cost of inbreeding depression. However, natural populations of species with unisexual gametophytes are characterized by a mixed mating system (Eppley et al., 2007). In such a system polyandry with selective embryo abortion may be able to decrease the realized costs of inbreeding and thus may explain the stability of mixed mating systems in species with unisexual gametophytes in face of inbreeding depression (Porcher and Lande, 2005).

One particularly important consequence of the freely swimming spermatozoids (as in mosses) is that fertilization can only occur among individuals in close proximity (McQueen, 1985; Wyatt, 1994; Crum, 2001; Bisang et al., 2004). This obviously limits the distance between successfully mating male and female gametophytes. Furthermore, owing to the leptokurtic distribution of spore dispersal, a female plant is expected to be surrounded mainly by the haploid progeny of its sporophyte (Longton, 1997; Sundberg, 2005; Gunnarsson et al., 2007). Consequently, mating is likely to occur among haploid siblings. Therefore, in the absence of a mechanism to distinguish among male gametes with different genetic relatedness to the female gametophyte, significant levels of inbreeding are expected in populations of unisexual gametophytes. These circumstances and the fitness costs associated with sporophytic inbreeding depression in bryophytes having separate sexes may trigger the evolution of mechanisms that promote outcrossing (Shaw, 2000; Taylor et al., 2007). As female plants are assumed to have only limited ability to assess the quality of their male partners before fertilization (e.g. the archegonial neck may have a filtering function), polyandry coupled with a postfertilization selection process could provide a mechanism for selection among numerous male partners.

In this study we investigate the extent of multiple paternity and inbreeding depression for the first time in natural populations of mosses using the peatmoss, Sphagnum lescurii Sullivant in A. Gray, as a model system. We address a series of general questions, taking advantage of the moss life cycle to obtain a detailed resolution of the mating system. (1) To what extent are multiple diploid sporophytes attached to a single, haploid female gametophyte fathered by different males (multiple paternity)? We test this by genotyping the maternal gametophyte plant and each attached sporophyte using microsatellite markers. As we then know the genotype of the female gamete (gametophyte) that bears the diploid sporophyte, we can obtain the genotype of the male gamete (gametophyte) by simple subtraction. (2) What is the average level of inbreeding in this population and how do individual sporophytes vary in the level to which they are inbred? (3) Is sporophyte fitness related to the genotypes of the maternal and paternal gametophytes (that is, gametes); specifically, can we detect evidence of inbreeding depression? We also assess the extent of spatial genetic structure in the population as this may promote fertilization among close relatives. Finally, we discuss the possible roles and evolutionary implications of polyandry in bryophytes.

\section{Materials and methods}

\section{Model species, plant material, and measuring of sporophyte traits}

$S$. lescurii has unisexual (dioicous) gametophytes but is characterized by frequent sporophyte production and occurrence of multiple sporophytes on individual female shoots. Young peatmoss sporophytes are surrounded by the perichaetial leaves of the female gametophyte and remain embedded for most of their life span. Unripe sporophytes are green and slowly turn black as they mature. In contrast to the majority of mosses, the peatmoss sporophyte consists of a spherical capsule and lacks a visible seta (stalk). When sporophytes are mature the seta is replaced by an extension of the maternal gametophyte, the pseudopodium, which enables successful spore dispersal by elevating the sporophyte above the female plant. As the pseudopodium is part of the female gametophyte, its elongation represents maternal investment.

S. lescurii samples were collected from a population in Richmond County, North Carolina. The species forms a continuous mat at the margin of Lake Broadacres, with a large proportion of gametophytes bearing multiple sporophytes. We followed two different sampling strategies to estimate the extent of spatial genetic structure, multiple paternity, sporophyte heterozygosity, and the relationship between heterozygosity and capsule diameter in the population. For the spatial analysis, a portion of the mat with abundant sporophyte production was intensively sampled in a $130 \mathrm{~cm} \times 169 \mathrm{~cm}$ sampling unit. Within this unit, a grid of $13 \mathrm{~cm} \times 13 \mathrm{~cm}$ cells was established and gametophytes were sampled at each intersection. Although both sterile and fertile gametophytes were collected, only sporophyte-bearing shoots were used in the final analyses. To increase the sporophyte-bearing females for analyses of parentage and inbreeding, additional samples were collected along the margins of the lake with a minimum distance of $3 \mathrm{~m}$ among consecutive samples. In total, 43 maternal shoots (29 from the grid and 14 along the lake margin) were sampled. One data set consisting only of plants sampled from the grid was used to assess spatial population structure and mating patterns. The second data set including all females and their attached sporophytes was used to estimate inbreeding levels and the relationship between heterozygosity and capsule diameter. 
Plants were brought to the lab and each maternal plant was screened for the occurrence of sporophytes under a dissecting microscope. Sporophytes were classified by developmental stages based on the color of the capsule (black capsule, ripe; green or yellow capsule, unripe) and on the position of the capsule relative to the perichaetial leaves (exerted; embedded). After coding the developmental stage of the sporophytes, the diameter of the capsule was measured to the nearest $0.1 \mathrm{~mm}$ with a calibrated ocular micrometer. As capsule diameter and spore number are correlated in Sphagnum (Sundberg and Rydin, 1998), capsule size served as a measure of sporophytic fitness (that is, the number of gametophyte progeny it produces).

\section{Microsatellite analyses}

DNA was extracted from 288 samples (gametophytes and sporophytes) using a modified CTAB protocol according to Shaw et al. (2003). At the end of the isolation process the DNA pellet was resuspended in $40 \mu \mathrm{l}$ of TE.

Thirty microsatellite loci (Shaw et al., 2008) were screened for a subset of the sporophyte and gametophyte samples and 14 polymorphic markers (locus nos. 1, 4, 5, $7,9,10,12,20,14,16,17,18,22,26$ in Shaw et al., 2008) showing consistent and clear amplification in both generations were used to genotype all 288 samples. Polymerase chain reaction conditions and multiplexing followed the protocols described in Shaw et al. (2008) with the modification that $1.5 \mu \mathrm{l}$ of undiluted DNA was used in case of the sporophytes to secure unambiguous amplification. Products were resolved on an ABI 3730 sequencer using a GS500 size standard (Applied Biosystems, Foster City, CA, USA). Size determinations and genotype assignments were made using GeneMarker 1.30 software (Softgenetics, State College, PA, USA).

\section{Statistical analysis}

To describe the genetic diversity of each locus, the number of alleles and Nei's unbiased gene diversity (Nei, 1987) per locus were estimated using the total data set including all haploid female and inferred male gametophytes. The significance of linkage disequilibrium among all pairs of loci was also investigated on the same haploid data set but we retained only one individual for each genetic clone (clone corrected data set). Calculations were conducted using FSTAT 2.9.3.2 (Goudet, 2001).

Paternity of each sporophyte was determined by comparing the multilocus genotype of the haploid maternal gametophyte with that of the diploid sporophyte generation attached to it. In bryophytes, owing to haploidy of the gametophytes, paternal multilocus genotypes can be unambiguously inferred by subtracting the mother's genotype from that of the sporophyte. To describe the degree of multiple paternity per mother plant (haploid shoot) we first calculated the number of different genetic fathers $(K)$ and the proportion of the sporophytes per shoot fertilized by different fathers. To assess the skew in paternity among sporophytes of the same shoot the effective number of fathers $\left(K_{E}\right.$; Bernasconi, 2003) was calculated using the following equation $K_{\mathrm{E}}=1 / \Sigma\left(p_{i}\right)^{2}$, where $p_{i}$ is the proportion of the sporophytes fertilized by each of the $i . . . n$ genetically distinct fathers. Theoretical maximum of $K_{\mathrm{E}}$ is equal to the number of donors when all shares of paternity are equal and thus it is dependent on the number of fathers involved. To enhance the comparability of $K_{\mathrm{E}}$ values a modified index, $K_{\mathrm{E}} / K$, was also estimated. This index ranges from 0 to 1 and reaches its maximum if each unique paternal genotype fathers an equal number of sporophytes per gametophyte shoot. Consequently, values close to 1 are expected if there is no skew in the paternity among the sporophytes of a mother. To assess whether observed values deviated significantly from a population mean of one, one-sample bootstrap tests were applied (Manly, 2007). Using $t$-statistics we tested the null hypothesis of single paternity $\left(K=1\right.$ and $\left.K_{\mathrm{E}}=1\right)$ and no reproductive skew $\left(K_{\mathrm{E}} / K=1\right)$ using 10000 bootstrap replicates. Probabilities for rejecting the null hypothesis were determined by counting up the proportion of bootstrap replicates in which the pseudo statistic equaled to or exceeded the observed value of the statistic (Manly, 2007). One-sample bootstrap tests were conducted in the $\mathrm{R}$ statistical package (R Development Core Team, 2006).

The data set consisting only of plants sampled from the grid was used to assess spatial population structure. If the majority of the spores of a mother plant are deposited primarily in its near neighborhood there should be a relationship between spatial and genetic distances. This hypothesis was investigated by regressing the pairwise kinship coefficients of genotypes on spatial distances using SPAGEDI 1.2 (Hardy and Vekemans, 2002). Regressions were conducted using untransformed and ln-transformed distances and using Ritland's kinship estimator because of its low variance (Ritland, 1996). The regression was also conducted using six distance classes containing approximately similar number of pairwise comparisons. Using both distance classes and simple regression allowed us to accurately detect the scale and the strength of spatial structure in the population. Spatial genetic structure of female and inferred male genotypes was investigated separately. To test whether the slope of the regression line differed significantly from zero spatial coordinates were randomly permuted among female individuals 10000 times (similar to a Mantel test; see Hardy and Vekemans, 2002). A similar test was used on paternal genotypes but with the difference that spatial coordinates of mothers were randomly permuted among the groups of fathers per mother. In the distance class analyses, 95\% confidence intervals of the average kinship coefficients were obtained by similar permutations. It is important to note that we did not sample male gametophytes directly in this study and analyses of spatial structure in fathers are based on inferred genotypes from sampling their sporophyte progeny.

If spatial genetic structure is present and sperm dispersal is limited, correlated paternity is expected among sporophytes of a particular mother plant. We tested for correlated paternity among sporophytes of female plants by randomly assigning paternal genotypes to mothers and calculating the average kinship coefficient of paternal genotypes per mother. Permutation was conducted 10000 times and observed and expected values of the average kinship coefficients among paternal genotypes within mothers were compared using a onetailed test in SPAGEDI 1.2 (Hardy and Vekemans, 2002).

To investigate the level of inbreeding of each sporophyte individual inbreeding coefficients were estimated 
using Loiselle's method (Loiselle et al., 1995) with the software SPAGEDI 1.2 (Hardy and Vekemans, 2002). As sporophytes of a female gametophyte necessarily share the same maternal genotype they do not represent independent draws from independent mating events. Therefore, to get an estimate of Wright's inbreeding coefficient ( $F_{\mathrm{IS}}$, Wright, 1965) comparable with other studies we randomly sampled one sporophyte per mother, generating 1000 data sets. For each random replicate we calculated mean $F_{\text {IS }}$ by bootstrapping 100 times over loci. Locus-specific $F_{\text {IS }}$ estimates were obtained using the following formula $F_{\mathrm{IS}}=1-H_{\mathrm{o}} / H_{\mathrm{e}}$ $\left(H_{\mathrm{o}}\right.$ : observed heterozygosity; $H_{\mathrm{e}}$ : expected heterozygosity) and averaged over all loci. Calculations were carried out using a custom script written in the $\mathrm{R}$ statistical package ( $\mathrm{R}$ Development Core Team, 2006).

To investigate whether there is sporophytic inbreeding depression in the population the relationship between sporophyte size (capsule diameter) and level of individual inbreeding was assessed. As a measure of individual inbreeding the number of heterozygous loci per sporophyte, the homozygosity index (HL, Aparicio et al., 2006), and Loiselle's estimator of inbreeding (Loiselle et al., 1995) were calculated using SPAGEDI 1.2 (Hardy and Vekemans, 2002) and the $R$ statistical package ( $R$ Development Core Team, 2006). As developmental stage of the sporophyte (characterized by two features: ripeness (color) and embeddedness within the perichaetial leaves) may blur the heterozygosity-capsule diameter relationship, and multiple sporophytes of a female gametophyte do not represent independent observations, mixed linear models were applied. To allow for correlation in the response variable (sporophyte diameter) among sporophytes growing on the same female gametophyte, we fitted two independent mixed linear models to the data defining heterozygosity and sporophyte developmental stage (two separate models for ripeness and embeddedness) and their interaction as fixed factors, whereas the mother plant was entered as a random factor. Models were fitted using the method of restricted maximum likelihoods implemented in the nlme module of the $\mathrm{R}$ statistical package ( $\mathrm{R}$ Development Core Team, 2006).

If female gametophytes preferentially support more heterozygous sporophytes then exerted sporophytes (on an elongated pseudopodium) are expected to be more heterozygous than embedded ones. In contrast, this difference is not expected between ripe and unripe sporophytes if pseudopodium elongation is driven primarily by sporophyte heterozygosity per se rather than differential support by the mother. We used a Mann-Whitney $U$-test to investigate whether embedded and exerted sporophytes differ in their levels of heterozygosity. The $U$-test was conducted using the R statistical package (R Development Core Team, 2006).

\section{Results}

Genetic diversity, multiple paternity, and paternity skew From the 14 loci, 11 produced unambiguously scorable fragments and were variable; these were used in the final analyses. Nei's unbiased heterozygosity (Nei, 1987) ranged between 0.115 and 0.540 with an average value of 0.362 across loci for all sporophytes sampled. All loci had two allelic states, except locus 17, which had three alleles. No significant linkage disequilibrium was found among any pairwise combinations of loci after a Bonferroni correction (results not shown).

The average number of sporophytes per female shoot was 6 and ranged between 2 and 15. More than half (mean 64\%, range 0-100\%) of the multiple sporophytes per female shoot showed different paternal genotypes and only 2 females out of the 43 investigated had sporophytes sharing the same paternal genotype. On average, approximately only one fourth (mean 0.27, range $0-1$ ) of the sporophytes per female shoot shared the same genetic father.

The mean number of paternal genotypes per female shoot $(K)$ was around four (mean 3.65, range 1-8), significantly different from a population mean of one (one-sample bootstrap test, $t=11.39, P<10^{-5}$ ). Similarly, the effective number of fathers $\left(K_{\mathrm{E}}\right)$ was approximately three (mean 3.22, range 1-7), which again showed significant deviation from the null hypothesis of one effective paternal genotype per female shoot (one-sample bootstrap test, $\left.t=9.55, P<10^{-5}\right)$. To describe the paternity skew among multiple sporophytes of the same female shoot, we calculated a modified index of the effective number of fathers $\left(K_{\mathrm{E}} / K\right)$. As this index is meaningless when all sporophytes of a maternal shoot share the same genotype, two female gametophytes were omitted from the calculation. After omitting these individuals, the modified index was on average 0.86 (range 0.64-1.00), which was significantly different from a population mean of 1 (one-sample bootstrap test, $t=7.94, P<10^{-5}$ ), suggesting a skew in paternity among multiple sporophytes of a single female individual.

\section{Spatial kinship structure and correlated paternity}

These analyses are based on plants sampled from the spatial grid; 14 maternal gametophytes and their sporophyte offspring collected elsewhere along the lake margin were not included. The Mantel test showed a significant negative relationship among pairwise spatial distances and kinship coefficients for both maternal and paternal (haploid) genotypes (Table 1). Significance of the relationship was higher when based on ln-transformed distances. Significant spatial structure was also evident from autocorrelation analyses using predefined distance classes (Figure 1). Average kinship coefficients were higher than expected by chance at a scale of 15$20 \mathrm{~cm}$. In contrast, average kinship values tended to be lower at larger spatial scales $(50-90 \mathrm{~cm})$ but this was significant in fathers but not in mothers. The significance of kinship values varied in relation to distance class widths; however, significantly higher kinship values were consistently found at the smallest spatial scales regardless of how the classes were defined. Random permutation of paternal genotypes among sporophytebearing female plants showed that fathers of sporophytes attached to a single female were more closely related than a random sample of fathers in the population (average kinship per mother $=0.240$, mean expected kinship $=0.064,95 \%$ CI $=0.034-0.098)$.

\section{Population and individual level inbreeding}

Including all sporophytes, the estimate of Wright's fixation coefficient $\left(F_{\mathrm{IS}}\right)$ was highly negative $(-0.418$, 
Table 1 Estimated pairwise kinship coefficients (Ritland, 1996) regressed on the raw and ln-transformed spatial distances among individuals

\begin{tabular}{lccccc}
\hline & Number of pairs & Slope & Intercept & $\mathrm{R}^{2}$ & Significance (one-tailed test) \\
\hline Female genotypes & \multirow{2}{*}{406} & & & & \\
Raw distances & & -0.0020 & 0.0901 & 0.0161 & 0.0402 \\
Ln distances & 406 & -0.0325 & 0.1338 & 0.0166 & 0.0191 \\
Inferred groups of male genotypes per female shoot & & -0.0015 & 0.0877 & 0.0058 & 0.0120 \\
Raw distances & & -0.0236 & 0.1196 & 0.0068 & 0.0041 \\
Ln distances & & &
\end{tabular}

Significance of the slope was assessed by randomly permuting individuals (in case of the female genotypes) or inferred groups of male genotypes per female shoot among spatial locations 10000 times.
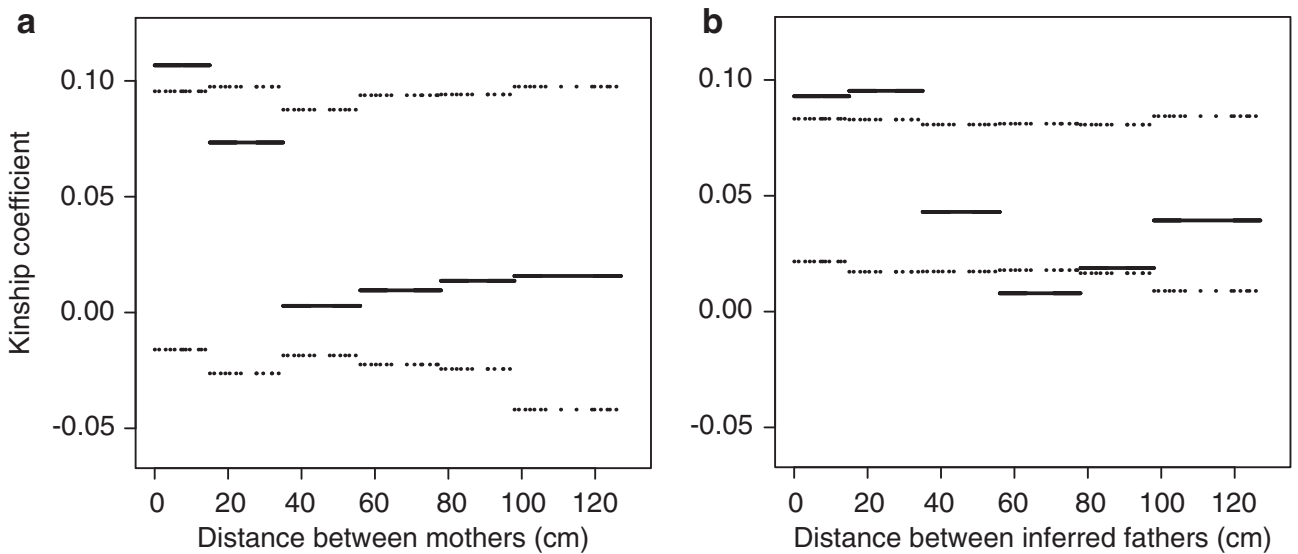

Figure 1 Results of the spatial autocorrelation analyses for haploid female (a) and inferred male genotypes (b) using predefined distance classes. Thick solid horizontal lines represent average observed kinship values within distance classes. Dashed horizontal lines delimit the 95\% CIs of the average kinship values for each distance class expected under the null hypothesis of no spatial genetic structure; $95 \%$ CIs were estimated by randomly permuting individuals among spatial locations 10000 times.

95\% bootstrap CI: -0.491 to -0.356$)$. In contrast, if we randomly sampled one sporophyte per female plant correcting for the fact that sporophytes of a female shoot always share the same maternal genotype the fixation index was not significantly different from zero $(-0.0153$, 95\% bootstrap CI: -0.1415-0.1217). Assuming inbreeding equilibrium an average selfing rate can be estimated $\left(S=2 F_{\mathrm{IS}} /\left(1+F_{\mathrm{IS}}\right)\right)$, which was not significantly different from zero $(S=-0.0405$, 95\% bootstrap CI: $-0.3296-$ 0.2170).

Individual inbreeding coefficients were also estimated as within-individual kinship coefficients. Individual inbreeding coefficients ranged between -0.8 and 1.6 with a mean of -0.0166 . The distribution of inbreeding coefficients shows that outcrossed and inbred sporophytes are present with approximately similar proportions (Figure 2).

\section{Relationship between heterozygosity versus sporophyte size and development}

Sporophyte size (measured as capsule diameter) was positively and significantly correlated with the level of sporophyte heterozygosity (Table 2; Figure 3). This relationship was largely independent of the measure of sporophyte heterozygosity used; therefore, only results based on the number of heterozygous loci are shown. The developmental stage of the sporophyte, measured as ripeness (color) or embeddedness, did not have a significant influence on the slope (no significant interaction term) or intercept of the relationship. Furthermore,

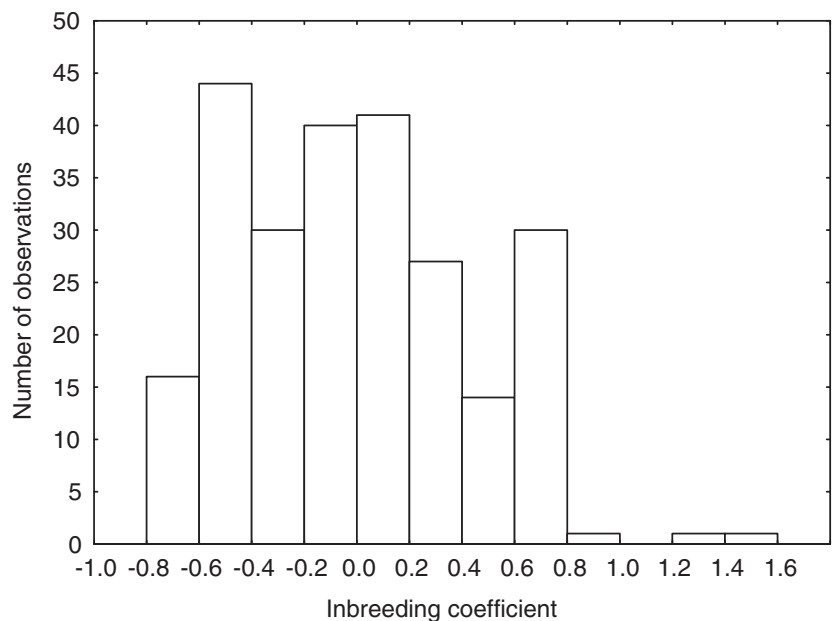

Figure 2 Distribution of within-individual inbreeding coefficients for sporophytes calculated following Loiselle et al. (1995).

sporophyte ripeness and embeddedness could be removed from the model without significant reduction in explanatory power. However, the heterozygosity $\times$ embeddedness term was only marginally nonsignificant. In contrast, exerted sporophytes were significantly more heterozygous than embedded ones (Mann-Whitney $U=5899, P=0.036$ ) whereas unripe and ripe sporophytes (green and black) did not differ significantly in their level of heterozygosity (Mann-Whitney $U=3384$, $P=0.9481)$. The same results were obtained with a linear 
Table 2 Results of two independent mixed linear models for the effect of sporophyte heterozygosity at two levels of sporophyte developmental stage on the response variable of sporophyte capsule diameter

\begin{tabular}{lrcc}
\hline Effect & d.f. & $F$ & $\mathrm{P}$ \\
\hline Sporophyte embeddedness & 1 & 0.5955 & 0.5522 \\
Heterozygosity & 1 & 3.4297 & 0.0007 \\
Sporophyte embeddedness $\times$ heterozygosity & 1 & 1.9364 & 0.0542 \\
Residual & 199 & & \\
Sporophyte ripeness & 1 & 0.1057 & 0.9160 \\
Heterozygosity & 1 & 3.2930 & 0.0012 \\
Sporophyte ripeness $\times$ heterozygosity & 1 & 1.1744 & 0.2416 \\
Residual & 199 & & \\
\hline
\end{tabular}

Heterozygosity and sporophyte developmental stage were entered as fixed factors whereas female gametophytes as random factor.

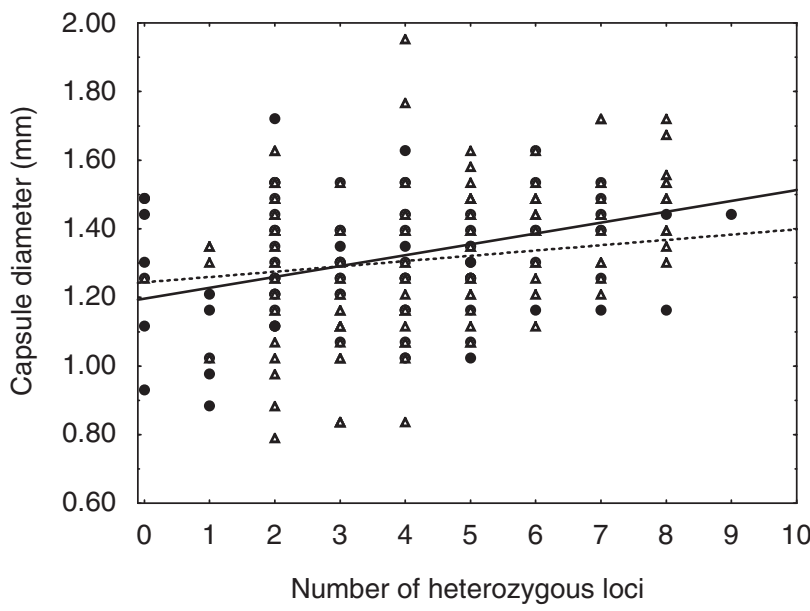

Figure 3 Relationship between sporophyte heterozygosity and capsule diameter $(\beta=0.3572$, s.e. $=0.1116, t=3.2001, P=0.0016$; simple linear model with female shoots defined as random factors). Symbols represent data points of embedded (solid dots) and exerted (empty triangles) sporophytes, respectively. Sporophyte ripeness or embeddedness had no or only marginally significant influence on the slope or intercept of the regression. This is shown by the two regression lines fitted for embedded (dashed) and exerted (solid) sporophytes separately.

mixed model (fixed factor: sporophyte embeddedness, response variable: heterozygosity, random factor: female gametophyte) taking into account the possible correlation in heterozygosity among sporophytes of a female shoot.

\section{Discussion}

\section{The occurrence and extent of multiple paternity in bryophytes}

Estimating the occurrence and extent of multiple paternity in natural populations of plants is important for assessing male reproductive success and the opportunity for postpollination selection (Snow and Lewis, 1993; Bernasconi, 2003). Life cycles of flowering plants and bryophytes differ in numerous important aspects, specifically; bryophytes have only limited opportunity to assess the quality of their mating partners before fertilization (Shaw, 2000). In such a system postfertilization selection may be a viable mechanism to improve sporophyte quality. Using a moss for these studies permits insight into the success of individual haploid gametes in effecting fertilization and how the fitness of their diploid progeny varies according to parentage. The fitness of seed plant gametes is either zero or one because each is genetically unique and can fertilize just one female. In mosses, gametophytes produce thousands (millions) of genetically identical gametes and there is great potential for variation in fitness.

Here, we show that multiple paternity is a common phenomenon in a dioicous moss species producing numerous sporophytes per female shoot. On average, more than half the sporophytes on each female plant had different paternal genotypes, providing ample opportunity for postfertilization selection. These findings are in line with the observation that multiple paternity frequently occurs in seed plants (for a review see Bernasconi, 2003). In addition, there was a skew in paternity per female shoot, suggesting that certain paternal genotypes fathered more sporophytes than others. Male gametophyte reproductive success in another moss, Polytrichum formosum, was significantly correlated with distance to the female, and with male clone size (Van der Velde et al., 2001). Both of these could be explanatory for male success in S. lescurii but this could not be tested with our data set because male gametophytes were not sampled.

As we determined paternal genotypes by comparing maternal and sporophyte genotypes, the absolute frequency of male genotypes in the population remains unknown. This is an inherent limitation of the study system because male reproductive structures are usually lacking when sporophytes mature, which prohibits sexing of sterile male shoots. Therefore, we do not know whether the skew in paternity mirrors male genotype abundances in the population or differences in the fertilization success of male genotypes regardless of their abundance. Critical assessment of paternity skew should include a comparison of expected and observed frequencies of paternity measuring the abundance of each male genotype in the population. Nevertheless, it is safe to say that certain male genotypes fathered more sporophytes than others and reproductive skew among male genotypes exists in natural populations of $S$. lescurii. In future studies, sex-specific genetic markers may allow direct estimation of fertilization success for each male genotype and help to clarify how life history traits influence male fitness in dioicous bryophytes.

Mosses rarely produce more than one mature sporophyte from a single perichaetium (reproductive bud) even though each perichaetium contains multiple archegonia (each containing an egg) (Longton, 1962; Shaw, 2000; Crum, 2001). However, a single female gametophyte forms multiple perichaetial buds and many species, like $S$. lescurii, can produce more than one sporophyte per female clone (Innes, 1990; Van der Velde et al., 2001; Cronberg et al., 2006). Female gametophytes in most species of Sphagnum commonly support multiple attached sporophytes. However, the presence of more than 10 sporophytes per female shoot, as observed in the present population of S. lescurii, rarely occurs among mosses, including Sphagnum. In another population of this species currently under study, female gametophytes rarely have more than six attached sporophytes (unpublished data). Although the high number of sporophytes 
on female gametophytes of S. lescurii may be exceptional, there is opportunity for multiple paternity in other mosses. Even those species that generally produce only one perichaetial bud per female plant have multiple receptive archegonia in that bud and casual observations indicate that often more than one egg is fertilized. A few species are characterized by polysetous buds (i.e. more than one sporophyte regularly matures from a single perichaetium), but this is generally a species-specific trait (e.g. the moss species, Dicranum polysetum) and in most taxa additional fertilized eggs stop developing at the embryo stage, yielding a single mature sporophyte per perichaetium (Longton and Schuster, 1983; Longton, 1994). Genotyping such abortive sporophytes to determine if there is a correlation between sporophyte genotype and development to maturity presents logistical problems and has not yet been undertaken. Nevertheless, this observation, along with the fact that most mosses are clonal organisms in which multiple ramets of a single clone can parent sporophytes suggests that multiple paternity and the potential for selective provisioning of sporophyte offspring by maternal gametophytes may be common in mosses.

\section{Evolutionary implications of multiple paternity in bryophytes}

In flowering plants, multiple paternity may improve the fitness of an individual through increasing seed set, weight of individual seeds, and genetic diversity of the progeny. It can also function as a defense mechanism against males carrying a meiotic drive allele and provide the opportunity for postpollination selection (Ellstrand and Marshall, 1986; Armbruster and Rogers, 2004; Bernasconi et al., 2004; Teixeira et al., 2009). The role of multiple paternity in the evolution of the bryophyte life cycle is less clear but its prevalence in the species studied here points to its relevance. As bryophytes have only limited ability (if any) to predict the quality of their mates and generally lack structures (such as a style) facilitating competition among mates before fertilization, selection is expected to promote mating with numerous possible males, with postfertilization selection. Postfertilization selection through the selective abortion of fertilized ovules can increase fitness and may be an important factor driving mating system evolution in flowering plants (Korbecka et al., 2002; Porcher and Lande, 2005). Similarly, the opportunity for postfertilization selection has been proposed to explain the production of multiple embryos in homosporous pteridophytes if the advantage gained by supporting the best sporophyte overrides the costs of the selective abortion process (Haig and Westoby, 1988).

In bryophytes, experimental evidence suggests that prefertilization male reproductive investment is similar to or greater than that of females even with sporophyte abortion (Longton and Greene, 1969; Miles et al., 1989; Stark et al., 2000; but see Bisang et al., 2006). However, female reproductive investment always overrides male costs if sporophytes reach maturity (Ehrlén et al., 2000; Stark et al., 2000; Bisang and Ehrlén, 2002). The simple structure of the peatmoss sporophyte (lacking a foot and a real seta) and the weakly developed interface among sporophyte and gametophyte generations (placental tissue) indicate that abortion of young zygotes and sporophytes may also be of low cost (Ligrone and Rezaglia, 1989; Buck and Goffinet, 2000). If this is true, this would support the notion that multiple paternity may act to promote postfertilization selection in bryophytes.

Dioicous bryophytes such as S. lescurii are thought to have genetic sex determination through the segregation of sex chromosomes (Ramsay and Berrie, 1982; Tanurdzic and Banks, 2004; McDaniel et al., 2007; Yamato et al., 2007). Under multiple paternity, evolutionary theory predicts contrasting interests for the male and female sexes (Haig and Wilczek, 2006). Females should allocate available resources equally to their sporophytes or support more vigorous ones to maximize their fitness. In contrast, paternal alleles should be selected to increase the allocation of maternal resources to their sporophyte progeny to achieve maximum fitness. If sporophyte size and fitness of the progeny are correlated, females may be supporting the most vigorous sporophytes. On the contrary, male genotypes are expected to favor increasing sporophyte size regardless of its genetic quality.

Bryophyte sporophytes need to be elevated above the gametophyte to successfully disperse spores (Sundberg, 2002, 2005). In peatmosses this is achieved by the elongation of a special part of the maternal gametophyte, the pseudopodium, which likely incurs costs only for the female plant (Schofield, 1985; Buck and Goffinet, 2000). Consequently, our observation that sporophytes on elongated pseudopodia are more heterozygous than those embedded in the perichaetial leaves supports the hypothesis that female shoots are actively involved in a postfertilization selection process. As less heterozygous sporophytes are smaller and contain fewer spores, females investing in larger sporophytes may be more successful in dispersing their genes. Moreover, larger capsules enhance short-distance dispersal and produce spores successful in immediate establishment (Miles and Longton, 1992; Sundberg and Rydin, 1998; Sundberg, 2005). Therefore, we hypothesize that heterozygosity may be an indicator of sporophyte vigor inducing elevated maternal investment in terms of nutrients and pseudopodium elongation. We cannot eliminate the possibility that there was a temporal shift in mating system in S. lescurii, with greater outcrossing early in the season, yielding more heterozygous sporophytes that had reached maturity when the plants were sampled for this study. However, the fact that young (green) and ripe (black) sporophytes do not differ in their level of heterozygosity contradicts this hypothesis.

\section{Level of sporophytic inbreeding and inbreeding depression}

We showed that $S$. lescurii has significant genetic structure on a small spatial scale. In addition, the correlated paternity per female shoot further corroborates short fertilization distances. These observations suggest that intergametophytic selfing and biparental inbreeding may be common in this population. In contrast, average levels of inbreeding and estimated selfing rates were not significantly different from a randomly mating population. Moreover, the $F_{I S}$ value calculated was considerably lower than the average value estimated for dioicous bryophytes $\left(F_{\mathrm{IS}}=0.41 \pm 11\right.$, Eppley et al., 2007). However, intergametophytic selfing 
and biparental inbreeding was present, because approximately half the sporophytes showed some level of inbreeding. It is also worth noting that our results show mixed mating system in $S$. lescurii, with sporophytes ranging from highly inbred to highly outcrossed. There are several nonexclusive hypotheses that may explain this observation.

As highlighted by Eppley et al. (2007), negative $F_{\text {IS }}$ values may not be uncommon in dioicous bryophytes. Negative values can arise if female shoots in a population belong to one genetic clone and male and female genotypes have few alleles in common. However, clonality and differences in allele frequencies among sexes cannot explain the zero mean value of $F_{\mathrm{IS}}$ observed in S. lescurii. First, clonality was limited in our data set (36 different genets from 43 female gametophytes) and thus estimating $F_{\text {IS }}$ by resampling one sporophyte per female clone rather than per female individual provided very similar values $\left(F_{\text {IS }}\right.$ by resampling one sporophyte per clone: 0.0047 , 95\% bootstrap CI: -0.1319-0.1566). Second, allele frequencies of successful paternal and maternal genotypes were similar and not significantly different according to a population differentiation test $(P=0.07$, maximum-likelihood $G$ test in FSTAT 2.9.3.2, Goudet, 2001). In addition, a process promoting the union of genetically compatible gametes (less-related gametes), as hypothesized by McLetchie (1996), seems unlikely because hybrid sporophytes are frequently formed in natural populations of peatmosses (Cronberg and Natcheva, 2002; Flatberg et al., 2006; Natcheva and Cronberg, 2007; but see Van der Velde and Bijlsma, 2004).

Alternatively, because early arrested zygotes and very young sporophytes likely remained unsampled in our study, it can be hypothesized that intergametophytic selfing occurs with a significant frequency in the population but its presence is masked by the process of embryo abortion at an early developmental stage. Inbreeding depression is usually divided into early and late acting components (Husband and Schemske, 1996). Early inbreeding depression is caused by highly deleterious and recessive mutations that lead to the abortion of the embryos. The late acting component is because of nearly recessive and slightly deleterious mutations considered to be constant in expression over time. It is well known that embryo and sporophyte abortion frequently occurs in bryophytes in a density-dependent manner; however, it is unclear whether less heterozygous sporophytes have a higher likelihood of being aborted (Callaghan et al., 1978; Stark and Stephenson, 1983; Stark et al., 2000; Stark, 2001, 2002a,b). Experimental results show that sporophytic inbreeding depression is present in dioicous bryophyte species (Taylor et al., 2007). Therefore, selective abortion of inbred embryos may explain the high outcrossing rates found in $S$. lescurii but this hypothesis needs to be verified by further experiments.

If postfertilization selection acts in natural populations and allows the preferential abortion of the most inbred sporophytes, this has important consequences for the evolution of mating system in bryophytes. Theory predicts that selective abortion of embryos caused either by resource competition or reproductive compensation may stabilize low or moderate selfing rates in seed plants when resources are limited (Porcher and Lande, 2005). The same may apply to dioicous bryophyte species because selective abortion or reproductive compensation can decrease the realized cost of inbreeding depression while maintaining a high genetic load (Korbecka et al., 2002; Porcher and Lande, 2005). Thus, mixed mating systems of dioicous bryophyte species can be stable even if such species frequently experience intergametophytic selfing and the primary inbreeding depression is large.

In the only earlier study of inbreeding depression in mosses, signs of sporophytic inbreeding depression were found in a dioicous but not in a monoicous species (Taylor et al., 2007). Length of the seta and of the capsule was significantly reduced in selfed compared with outcrossed sporophytes. It has been proposed that this difference is because monoicous species can purge their genetic load through intragametophytic selfing (which yields a completely homozygous sporophyte) whereas dioicous species rarely self (intergametophytic selfing) and thus accumulate recessive deleterious mutations (Eppley et al., 2007; Taylor et al., 2007). We found that the level of sporophyte heterozygosity is significantly correlated with sporophyte size in S. lescurii, which is in line with earlier investigations (Taylor et al., 2007). Importantly, this relationship was not influenced by the ripeness and only marginally by the embeddedness of the sporophyte. Younger sporophytes were as heterozygous as older ones and thus there was no significant difference in the level of sporophyte heterozygosity over the course of the fertilization period. Nevertheless, sporophyte embeddedness had a larger effect on the slope of the heterozygosity-capsule diameter relationship than did sporophyte ripeness. This observation suggests a more pronounced effect of heterozygosity on capsule diameter in exerted sporophytes relying mainly on maternal resources (most of them are nonphotosynthetic). Overall, our results confirm the experimental finding that dioicous bryophytes show sporophytic inbreeding depression. It is still unknown, however, how this affects the fitness of the haploid progeny.

\section{Conclusions}

In this study we show for the first time that multiple paternity frequently occurs in this natural population of a dioicous moss species, $S$. lescurii. We also demonstrate that sporophytic inbreeding depression is present and that female shoots appear to preferentially elevate sporophytes with higher heterozygosity. These findings suggest that polyandry may have evolved to support mating with multiple males and to allow postfertilization selection probably regulated by the female shoot. If selective embryo abortion is also happening in natural populations this has important evolutionary implications for breeding system evolution in bryophytes. However, further studies are needed to clarify the extent of multiple paternity, the significance and mechanism of the heterozygosity-sporophyte size relationship, and the costs of female and male reproduction. Furthermore, the selective sporophyte abortion hypothesis needs to be experimentally verified.

\section{Acknowledgements}

We are grateful to Nuno Casimiro Vaz Silva for his help in fieldwork. Critical comments of three anonymous reviewers are greatly acknowledged. This research was 
supported by NSF grant DEB 0515749 to AJS and by an SNSF grant to PSZ.

\section{References}

Aparicio JM, Ortego J, Cordero PJ (2006). What should we weigh to estimate heterozygosity, alleles or loci? Mol Ecol 15: 4659-4665.

Armbruster WS, Rogers DG (2004). Does pollen competition reduce the cost of inbreeding? Am J Bot 91: 1939-1943.

Arnold SJ (1994). Bateman's principles and the measurement of sexual selection in plants and animals. Am Nat 144: 126-149.

Bateman AJ (1948). Intra-sexual selection in Drosophila. Heredity 2: $349-368$.

Bernasconi G (2003). Seed paternity in flowering plants: an evolutionary perspective. Perspect. Plant Ecol Evol Syst 6: 149-158.

Bernasconi G, Ashman TL, Birkhead TR, Bishop JD, Grossniklaus U, Kubli E et al. (2004). Evolutionary ecology of the prezygotic stage. Science 303: 971-975.

Birkhead TR, Møller AP (1998). Sperm Competition and Sexual Selection. Academic Press: London, UK.

Bisang I, Ehrlén J (2002). Reproductive effort and cost of sexual reproduction in female Dicranum polysetum. Bryologist 105: 384-397.

Bisang I, Ehrlén J, Hedenäs L (2004). Mate limited reproductive success in two dioicous mosses. Oikos 104: 291-298.

Bisang I, Ehrlén J, Hedenäs L (2006). Reproductive effort and costs of reproduction do not explain female-biased sex ratios in the moss Pseudocalliergon trifarium (Amblystegiaceae). Am J Bot 93: 1313-1319.

Buck WR, Goffinet B (2000). Morphology and classification of mosses. In: Shaw AJ, Goffinet B (eds). Bryophyte Biology. Cambridge University Press: Cambridge, MA, pp 71-124.

Callaghan TV, Collins NJ, Callaghan CH (1978). Photosynthesis, growth and reproduction of Hylocomium splendens and Polytrichum commune in Swedish Lapland. Oikos 31: 73-88.

Campbell D (1998). Multiple paternity in fruits of Ipomopsis aggregata (Polemoniaceae). Am J Bot 85: 1022-1027.

Cornell SJ, Tregenza T (2007). A new theory for the evolution of polyandry as a means of inbreeding avoidance. Trans $R$ Soc London B Biol Sci 274: 2873-2879.

Cronberg N, Natcheva R (2002). Hybridization between the peat mosses, Sphagnum capillifolium and S. quinquefarium (Sphagnaceae, Bryophyta) as inferred by morphological characters and isozyme markers. Plant Syst Evol 234: 53-70.

Cronberg N, Rydgren K, Økland RH (2006). Clonal structure and genet-level sex ratios suggest different roles of vegetative and sexual reproduction in the clonal moss Hylocomium splendens. Ecography 29: 95-103.

Crum H (2001). Structural Diversity of Bryophytes. University of Michigan Herbarium: Ann Arbor, MI.

Ehrlén J, Bisang I, Hedenäs L (2000). Costs of sporophyte production in the moss, Dicranum polysetum. Plant Ecol 149: 200-217.

Ellstrand NC, Marshall DL (1986). Patterns of multiple paternity in populations of Raphanus sativus. Evolution 40: 837-842.

Eppley SM, Taylor PJ, Jesson LK (2007). Self-fertilization in mosses: a comparison of heterozygote deficiency between species with combined versus separate sexes. Heredity $\mathbf{9 8}$ 38-44.

Flatberg KI, Thingsgaard K, Såstad SM (2006). Interploidal gene flow and introgression in bryophytes: Sphagnum girgensohnii $\times$ S. russowii, a case of spontaneous neotriploidy. J Bryol 28: 27-37.

Frentiu FD, Chenoweth SF (2008). Polyandry and paternity skew in natural and experimental populations of Drosophila serrata. Mol Ecol 17: 1589-1596.

Goudet J (2001). FSTAT, a program to estimate and test gene diversities and fixation indices (version 2.9.3). Available from http://www.unil.ch/izea/softwares/fstat.html. Updated from Goudet (1995).

Gunnarsson U, Lönn M, Shaw AJ (2007). Local-scale genetic structure in the peatmoss, Sphagnum fuscum. Mol Ecol 16: 305-312.

Haig D, Westoby M (1988). Sex expression in homosporous ferns: an evolutionary perspective. Evol Trends Plants 2: 111-119.

Haig D, Wilczek A (2006). Sexual conflict and the alternation of haploid and diploid generations. Philos Trans $R$ Soc London $B$ Biol Sci 361: 335-343.

Hardy OJ, Vekemans X (2002). SPAGeDi: a versatile computer program to analyse spatial genetic structure at the individual or population levels. Mol Ecol Notes 2: 618-620.

Husband BC, Schemske DW (1996). Evolution of the magnitude and timing of inbreeding depression in plants. Evolution 50: 54-70.

Innes DJ (1990). Microgeographic genetic variation in the haploid and diploid stages of the moss Polytrichum juniperinum Hedw. Heredity 64: 331-340.

Knight TM, Steets JA, Vamosi JC, Mazer SJ, Burd M, Campbell DR et al. (2005). Pollen limitation of plant reproduction: pattern and process. Annu Rev Ecol Evol Syst 36: 467-487.

Korbecka G, Klinkhamer PGL, Vrieling K (2002). Selective embryo abortion hypothesis revisited-a molecular approach. Plant Biol 4: 298-310.

Ligrone R, Rezaglia KS (1989). The ultrastructure of the placenta in Sphagnum. New Phytol 111: 197-201.

Loiselle BA, Sork VL, Nason J, Graham C (1995). Spatial genetic structure of a tropical understory shrub, Psychotria officinalis (Rubiaceae). Am J Bot 82: 1420-1425.

Longton RE (1962). Polysety in the British bryophyta. Trans $\mathrm{Br}$ Bryol Soc 4: 326-333.

Longton RE (1994). Reproductive biology in bryophytes: the challenge and the opportunities. J Hattori Bot Lab 75: 1-13.

Longton RE (1997). Reproductive biology and life-history strategies. In: Longton RE (ed). Advances in Bryology, Population Studies. Gebr. Borntraeger Verlagsbuchhandlung, Science Publishers: Stuttgart, pp 65-103.

Longton RE, Greene SW (1969). The growth and reproductive cycle of Pleurozium schreberi (Brid.). Mitt Ann Bot 33: 83-105.

Longton RE, Schuster RM (1983). Reproductive biology. In: Schuster RM (ed). New Manual of Bryology, vol. 1. Hattori Botanical Laboratory: Nichinan, pp 386-462.

Manly BFJ (2007). Randomization, Bootstrap and Monte Carlo Methods in Biology, 3rd edn. Chapman and Hall: New York, NY.

McDaniel SF, Willis JH, Shaw AJ (2007). A linkage map reveals a complex basis for segregation distortion in an interpopulation cross in the moss Ceratodon purpureus. Genetics 176: 2489-2500.

McLetchie DN (1996). Sperm limitation and genetic effects on fecundity in the dioecious liverwort Sphaerocarpos texanus. Sex Plant Reprod 9: 87-92.

McQueen CB (1985). Spatial pattern and gene flow distances in Sphagnum subtile. Bryologist 88: 333-336.

Miles CJ, Longton RE (1992). Deposition of moss spores in relation to distance from parent gametophytes. J Bryol 17: 355-368.

Miles CJ, Odu EA, Longton RE (1989). Phenological studies on British mosses. J Bryol 15: 607-621.

Natcheva R, Cronberg N (2007). Recombination and introgression of nuclear and chloroplast genomes between the peat mosses, Sphagnum capillifolium and S. quinquefarium. Mol Ecol 16: 811-818.

Nei M (1987). Molecular Evolutionary Genetics. Columbia University Press: New York, NY.

Porcher E, Lande R (2005). Reproductive compensation in the evolution of plant mating systems. New Phytol 166: 673-684.

Portnoy DS, Piercy AN, Musick JA, Burgess GH, Graves JE (2007). Genetic polyandry and sexual conflict in the sandbar 
shark, Carcharhinus plumbeus, in the western North Atlantic and Gulf of Mexico. Mol Ecol 16: 187-197.

R Development Core Team (2006). R: A language and environment for statistical computing. R Foundation for Statistical Computing, Vienna, Austria. ISBN 3-900051-07-0, URLhttp:/ / www.R-project.org.

Ramsay H, Berrie G (1982). Sex determination in bryophytes. J Hattori Bot Lab 52: 255-274.

Ritland K (1996). Estimators for pairwise relatedness and individual inbreeding coefficients. Genet Res Cambridge 67: 175-185.

Schofield WB (1985). Introduction to Bryology. Macmillan Publishing Company: New York, NY.

Shaw AJ (2000). Population ecology, population genetics and microevolution. In: Shaw AJ, Goffinet B (eds). Bryophyte Biology. Cambridge University Press: Cambridge, MA, pp 369-402.

Shaw AJ, Cao T, Wang L-S, Flatberg KI, Flatberg B, Shaw B et al. (2008). Genetic variation in three Chinese peat mosses (Sphagnum) based on microsatellite markers, with primer information and analysis of ascertainment bias. Bryologist 111: 260-271.

Shaw AJ, Cox CJ, Boles SB (2003). Polarity of peatmoss (Sphagnum) evolution: who says mosses have no roots? Am J Bot 90: 1777-1787.

Snow AA, Lewis PO (1993). Reproductive traits and male fertility in plants: empirical approaches. Annu Rev Ecol Syst 24: 331-351.

Stark LR (2001). Widespread sporophyte abortion following summer rains in Mojave Desert populations of Grimmia orbicularis. Bryologist 104: 115-125.

Stark LR (2002a). Skipped consecutive reproductive cycles and extensive sporophyte abortion in the desert moss Tortula inermis correspond to unusual rainfall patterns. Can J Bot 80: 533-542.

Stark LR (2002b). New frontiers in bryology: phenology and its repercussions on the reproductive ecology of mosses. Bryologist 105: 204-218.

Stark LR, Mishler BD, McLetchie DN (2000). The cost of realized sexual reproduction: assessing patterns of reproductive allocation and sporophyte abortion in a desert moss. Am J Bot 87: 1599-1608.

Stark LR, Stephenson AG (1983). Reproductive biology of Entodon cladorrhizans (Bryopsida, Entodontaceae). II. Resource-limited reproduction and sporophyte abortion. Syst Bot 8: 389-394.

Stephenson AG (1981). Flower and fruit abortion: proximate causes and ultimate functions. Annu Rev Ecol Syst 19: 177-205.
Sundberg S (2002). Sporophyte production and spore dispersal phenology in Sphagnum: the importance of summer moisture and patch characteristics. Can J Bot 80: 543-556.

Sundberg S (2005). Sporophyte size positively influences shortrange spore dispersal in Sphagnum, but what happens further away? Oikos 108: 115-124.

Sundberg S, Rydin H (1998). Spore number in Sphagnum and its dependence on spore and capsule size. J Bryol 20: 1-16.

Tanurdzic M, Banks JA (2004). Sex-determining mechanisms in land plants. Plant Cell 16: S61-S71.

Taylor PJ, Eppley SM, Jesson LK (2007). Sporophytic inbreeding depression in mosses occurs in a species with separate sexes but not in a species with combined sexes. Am J Bot 94 1853-1859.

Teixeira S, Bernasconi G (2007). High prevalence of multiple paternity within fruits in natural populations of Silene latifolia, as revealed by microsatellite DNA analysis. Mol Ecol 16: $4370-4379$

Teixeira S, Foerster K, Bernasconi G (2009). Evidence for inbreeding depression and post-pollination selection against inbreeding in the dioecious plant Silene latifolia. Heredity 102: 101-112.

Tregenza T, Wedell N (2000). Genetic compatibility, mate choice and patterns of parentage: invited review. Mol Ecol 9: 1013-1027.

Trivers RL (1972). Parental investment and sexual selection. In: Campbell B (ed). Sexual Selection and the Descent of Man. Aldine-Atherton: Chicago, IL, pp 1871-1971.

Van der Velde M, Bijlsma R (2004). Hybridization and asymmetric reproductive isolation between the closely related bryophyte taxa Polytrichum commune and P. uliginosum. Mol Ecol 13: 1447-1454.

Van der Velde M, During HJ, Van de Zande L, Bijlsma R (2001). The reproductive biology of Polytrichum formosum: clonal structure and paternity revealed by microsatellites. Mol Ecol 10: $2423-2434$

Wiens D (1984). Ovule survivorship, brood size, life history, breeding systems and reproductive success in plants. Oecologia 64: 47-53.

Wright S (1965). The interpretation of population structure by F-statistics with special regard to systems of mating. Evolution 19: 395-420.

Wyatt R (1994). Population genetics of bryophytes in relation to their reproductive biology. J Hattori Bot Lab 76: 147-157.

Yamato KT, Ishizaki K, Fujisawa M, Okada S, Nakayama S, Fujishita $\mathrm{M}$ et al. (2007). Gene organization of the liverwort $Y$ chromosome reveals distinct sex chromosome evolution in a haploid system. Proc Natl Acad Sci USA 104: 6472-6477. 